\title{
Longitudinal alterations in health-related quality of life and its impact on the clinical course of patients with advanced hepatocellular carcinoma receiving sorafenib treatment
}

Masako Shomura ${ }^{1,4^{*}}$, Tatehiro Kagawa ${ }^{2}$, Haruka Okabe ${ }^{1}$, Koichi Shiraishi $^{2}$, Shunji Hirose ${ }^{2}$, Yoshitaka Arase ${ }^{2}$, Kota Tsuruya ${ }^{2}$, Sachiko Takahira ${ }^{3}$ and Tetsuya Mine ${ }^{2}$

\begin{abstract}
Background: This study aimed to identify the health-related quality of life (HRQOL) domains associated with prognosis by assessing longitudinal alterations in HRQOL in patients with advanced hepatocellular carcinoma receiving sorafenib.

Methods: We prospectively assessed HRQOL by administering the SF-36 questionnaire 3-monthly to consecutive patients with advanced hepatocellular carcinoma receiving sorafenib. We evaluated the impact of HRQOL on their overall survival and duration of treatment with sorafenib using Cox's proportional hazards model.

Results: There were 54 participants: 42 (78 \%) were male, the median age was 71 years, 24 (44\%) had hepatitis C virus infection, 33 (61 \%) had Child-Pugh scores of 5, and 30 (56 \%) had TNM stage IV hepatocellular carcinoma. The median overall survival and treatment duration were 9 and 5 months, respectively, and 40 patients (74\%) died. Thirteen patients receiving sorafenib over a 1-year period maintained all domain scores $>40$, without a significant decline during the treatment period. In contrast, physical functioning, physical role, and vitality scores declined continuously and significantly in the year before death (in the 40 patients who died). Previous curative treatment and physical functioning scores $\geq 40$ at baseline were significantly associated with longer overall survival by multivariate analysis. Social functioning scores $\geq 40$, absence of vascular invasion, and lower DCP value were significant predictors of longer treatment duration.
\end{abstract}

Conclusions: $\mathrm{HRQOL}$ was not significantly impaired in those patients who were able to complete a 1-year course of sorafenib treatment. Baseline physical functioning scores $\geq 40$ and social functioning scores $\geq 40$ were significantly associated with longer overall survival and longer treatment duration, respectively. Thus, HRQOL could be a valuable marker to predict the clinical course of patients with advanced hepatocellular carcinoma receiving sorafenib.

Keywords: Advanced hepatocellular carcinoma, Sorafenib, Health-related quality of life, Clinical course, Prognostic marker

\footnotetext{
* Correspondence: s-masako@tokai-u.jp

${ }^{1}$ Department of Nursing, Tokai University School of Health Sciences, Isehara,

Kanagawa, Japan

${ }^{4} 143$ Shimokasuya, Isehara-city, Kanagawa 259-1193, Japan

Full list of author information is available at the end of the article
} 


\section{Background}

Liver cancer is the third leading cause of cancer-related deaths worldwide [1]. The prognosis of patients with hepatocellular carcinoma (HCC) is poor because of the high recurrence rate and/or the presence of underlying chronic liver disease(s). Sorafenib, a small molecular inhibitor of several tyrosine protein kinases-vascular endothelial growth factor receptor, platelet-derived growth factor receptor, and Raf kinases-extends the median overall survival by nearly 3 months compared with placebo in patients with advanced $\operatorname{HCC}[2,3]$. However, adverse effects (such as hand-foot skin reactions, diarrhea, or weight loss) and the deterioration in liver function associated with its use, and progressive disease, limit the efficacy of sorafenib.

Quality of life is a multi-dimensional concept that includes subjective evaluation of both physical and mental aspects of life. More specifically, the term "health-related quality of life" (HRQOL) refers to a multidimensional concept that encompasses patients' perceptions of both negative and positive aspects of at least four dimensions: physical functioning, emotional well-being, social wellbeing, and spiritual well-being; and disease and treatmentrelated symptoms. HRQOL assessment is becoming an important component of health surveillance and an indicator of service needs and intervention outcomes. Furthermore, HRQOL could be used as a prognostic marker for patients with various types of cancer [4]. In particular, the baseline physical functioning domain has been associated with survival in patients with non-small cell lung cancer [5] and tumor-node-metastasis (TNM) stages III and IV colorectal cancer [6]. A recent study revealed that physical well-being, evaluated using the Functional Assessment of Cancer Therapy-Hepatobiliary, could be used as a prognostic marker in patients with various stages of HCC and cholangiocarcinoma [7]. However, few studies have explored the association of HRQOL and prognosis in patients with HCC. Targeted molecular therapy, now widely used for many types of cancers, is often accompanied by unique adverse effects, such as hand-foot skin reaction [8]. In terms of adverse effects, longitudinal follow-up for HRQOL is likely to facilitate clinical decision-making by correctly evaluating the patient's condition. Several studies have reported on changes in HRQOL in patients receiving targeted molecular therapy [9-12], but with controversial results. Sorafenib treatment was associated with a significant decrease in quality of life because of adverse effects in patients with HCC [12, 13] and advanced renal cell carcinoma [12]. In contrast, Miyake et al. could not identify a significant influence of sorafenib on HRQOL in patients with metastatic renal cell carcinoma [9]. Therefore, further evidence on the impact of sorafenib therapy on quality of life and clinical course is required.
In this study, we aimed to clarify longitudinal alterations in HRQOL in patients with advanced HCC [3] receiving sorafenib and to identify the HRQOL domains associated with prognosis.

\section{Methods \\ Patients}

We enrolled consecutive patients with advanced HCC who received sorafenib therapy from August 4, 2010 to April 7, 2015 at Tokai University Hospital. Eligibility criteria were as follows: (1) non-resectable advanced HCC; (2) resistance to, or no indication for, transcatheter arterial chemoembolization; (3) Child-Pugh class A or B [14]; (4) TNM criteria of Liver Cancer Study Group of Japan stage III or IV [15]; and (5) Eastern Cooperative Oncology Group Performance Status (ECOG PS) 0 or 1 [16]. Most patients received $800 \mathrm{mg}$ of sorafenib as an initial dose, but lower doses (including 200, 400, and $600 \mathrm{mg}$ ) were administered to certain patients, particularly those aged > 70 years or with Child-Pugh class B liver function. Nurses provided educational instructions when initiating sorafenib treatment and gave medical advice by telephone.

\section{Health-related quality of life assessment}

We prospectively assessed HRQOL using a Japanese version of the short form health survey (SF-36) $\mathrm{v} 2^{\mathrm{Tm}}$ [17]. We chose SF-36 because its Japanese national standard score was available. Patients completed this questionnaire every 3 months by self-report during their clinic visits. The questionnaire assessed eight domains for health status, with 36 questions covering both mental and physical aspects of health. These aspects included physical functioning; role limitations because of physical problems - referred to as role physical (RP); bodily pain; general health; vitality; social functioning; role limitations because of emotional problems-referred to as role emotional (RE); and mental health. Each domain was scored on a scale of $0-100$, with lower scores indicating poorer health status. A score of 50 points, considered the Japanese national standard, was used for comparison with study samples $[17,18]$. In this study, we chose a score of 40 points $-80 \%$ of the Japanese national standard-as the cut off value.

\section{Clinical evaluation}

Tumor measurements were performed using dynamic computed tomography (CT) or magnetic resonance imaging (MRI) before and every 3 months after initiation of sorafenib treatment. Assessment of disease control and progression was based on the modified Response Evaluation Criteria in Solid Tumors [19]. The disease control rate was defined as the percentage of patients with complete response, partial response, and stable disease 3 months after initiation of sorafenib. Adverse 
events were evaluated monthly using National Cancer Institute Common Toxicity Criteria (version 4.0) [20]. Patients were followed up until May 25, 2015 or death. The discontinuation of sorafenib was defined as the outcome for treatment duration in this study.

\section{Statistical analysis}

To analyze the changes in HRQOL scores, we used the Friedman test, Bonferroni correction, and Wilcoxon two-sample test for patients who continued sorafenib treatment over a 1-year period, and the Kruskal-Wallis or Mann-Whitney $U$ test for the 40 deceased patients. We analyzed the relationship between HRQOL, baseline characteristics, overall survival, and treatment duration using multiple logistic regression and Cox's proportional hazards regression model. Multivariate analysis was performed using the forward stepwise procedure (likelihood ratio). We also analyzed treatment discontinuation incidence using a competing risks approach (Gray's method). Medians and interquartile ranges (IQR) or means and standard deviations were used to describe non-parametric and parametric data, respectively. Categorical variables were represented in terms of proportions and frequency tables. $P$ values $<0.05$ were considered to indicate statistical significance. Statistical analysis was performed using $\mathrm{IBM}^{\ominus} \mathrm{SPSS}^{\odot}$ statistical software, version 23 for Windows (2015, Somers, NY).

\section{Results}

\section{Baseline patient characteristics}

Of the 54 patients participating in the study, 42 (78 \%) were male (Table 1 ). The median age was 71 years (range, 57-84 years). Nearly half of the patients $(44 \%)$ had hepatitis $\mathrm{C}$ virus (HCV) infection. Most patients (61 \%) had a Child-Pugh score of 5 (median score: 5.0 IQR: 5.0-6.0), and most (57 \%) had TNM stage IV HCC. The majority of patients (68 \%) had received curative therapy, such as surgical resection and radiofrequency ablation, before enrolment to the study.

We analyzed the association between each HRQOL domain score and patient characteristics at baseline. Female sex was associated with lower physical functioning domain scores than male sex (OR 0.167, $95 \% \mathrm{CI}$ $0.039-0.715, p=0.016$ ). Patients aged $<70$ years had significantly lower scores in the domain of general health (OR 0.280, 95 \% CI 0.080-0.984, $p=0.047$ ). Role physical domain scores was significantly higher the patients with previous curative treatment (34.8 \pm 11.5 $[$ mean $\pm \mathrm{SD}]$ points) than without $(31.1 \pm 17.3$ points $)$. Other domain scores were not significantly different in terms of baseline patient characteristics.
Table 1 Baseline demographic and clinical characteristics

\begin{tabular}{|c|c|c|}
\hline Variable & & $n(\%)$ \\
\hline Age, years & $\begin{array}{l}<70 \\
\geq 70\end{array}$ & $\begin{array}{l}24(44) \\
30(56)\end{array}$ \\
\hline Sex & $\begin{array}{l}\text { Male } \\
\text { Female }\end{array}$ & $\begin{array}{l}42(78) \\
12(22)\end{array}$ \\
\hline Etiology & $\begin{array}{l}\text { HCV } \\
\text { HBV } \\
\text { Alcohol-related } \\
\text { Unknown }\end{array}$ & $\begin{array}{l}24(44) \\
11(20) \\
7(13) \\
12(23)\end{array}$ \\
\hline Child-Pugh score, points & $\begin{array}{l}5 \\
\geq 6\end{array}$ & $\begin{array}{l}33(61) \\
21(39)\end{array}$ \\
\hline TNM staging & $\begin{array}{l}\text { III } \\
\text { IV }\end{array}$ & $\begin{array}{l}23(43) \\
31(57)\end{array}$ \\
\hline Vascular invasion & $\begin{array}{l}- \\
+\end{array}$ & $\begin{array}{l}40(74) \\
14(26)\end{array}$ \\
\hline Maximum tumor size, mm & $\begin{array}{l}<50 \\
\geq 50\end{array}$ & $\begin{array}{l}33(61) \\
21(39)\end{array}$ \\
\hline Previous therapy & $\begin{array}{l}\text { Curative } \\
\text { Other } \\
\text { None }\end{array}$ & $\begin{array}{l}35(65) \\
14(26) \\
5(9)\end{array}$ \\
\hline Serum alpha fetoprotein, $\mathrm{ng} / \mathrm{mL}$ & $\begin{array}{l}<100 \\
\geq 100\end{array}$ & $\begin{array}{l}25(54) \\
29(46)\end{array}$ \\
\hline $\mathrm{DCP}, \mathrm{mAU} / \mathrm{mL}^{\mathrm{a}}$ & $\begin{array}{l}<1000 \\
\geq 1000\end{array}$ & $\begin{array}{l}27(52) \\
25(48)\end{array}$ \\
\hline Initial dose of sorafenib, mg & $\begin{array}{l}200 \\
400 \\
600 \\
800\end{array}$ & $\begin{array}{l}10(19) \\
14(26) \\
6(11) \\
24(44)\end{array}$ \\
\hline
\end{tabular}

$D C P$ des-gamma-carboxy prothrombin, $H C V$ hepatitis $C$ virus, $H B V$ hepatitis $B$ virus

${ }^{\mathrm{a}} \mathrm{DCP}$ values were not available for two cases

\section{Treatment efficacy and adverse events}

Disease control was obtained in 27 patients (50\%): one (2\%) had complete response, five (9\%) had partial response, and 21 (39\%) had stable disease. In total, 40 patients $(74 \%)$ died. Almost all patients (98\%) experienced adverse events (Additional file 1: Figure S1). Common adverse events included anorexia (76\%), skin toxicity (72\%), fatigue (63\%), diarrhea (56\%), and weight loss (52 \%). There were no grade 4 or 5 adverse effects. Grade 3 adverse effects occurred in 27 patients (50\%). Of these, skin toxicity was most common (33 \%), followed by anorexia (15\%) and fatigue (9\%). Sorafenib was discontinued or the dose was reduced in $11(20 \%)$ and 16 patients (30\%), respectively, because of adverse events. At the end of observation period, sorafenib was withdrew in 42 patients. The reasons for withdrawal were as follows: disease progression (34 patients); adverse events of skin toxicity and diarrhea (two patients); complications such as stroke, pneumonia, and intracranial hemorrhage (three patients); and at the patient's request (three patients). 

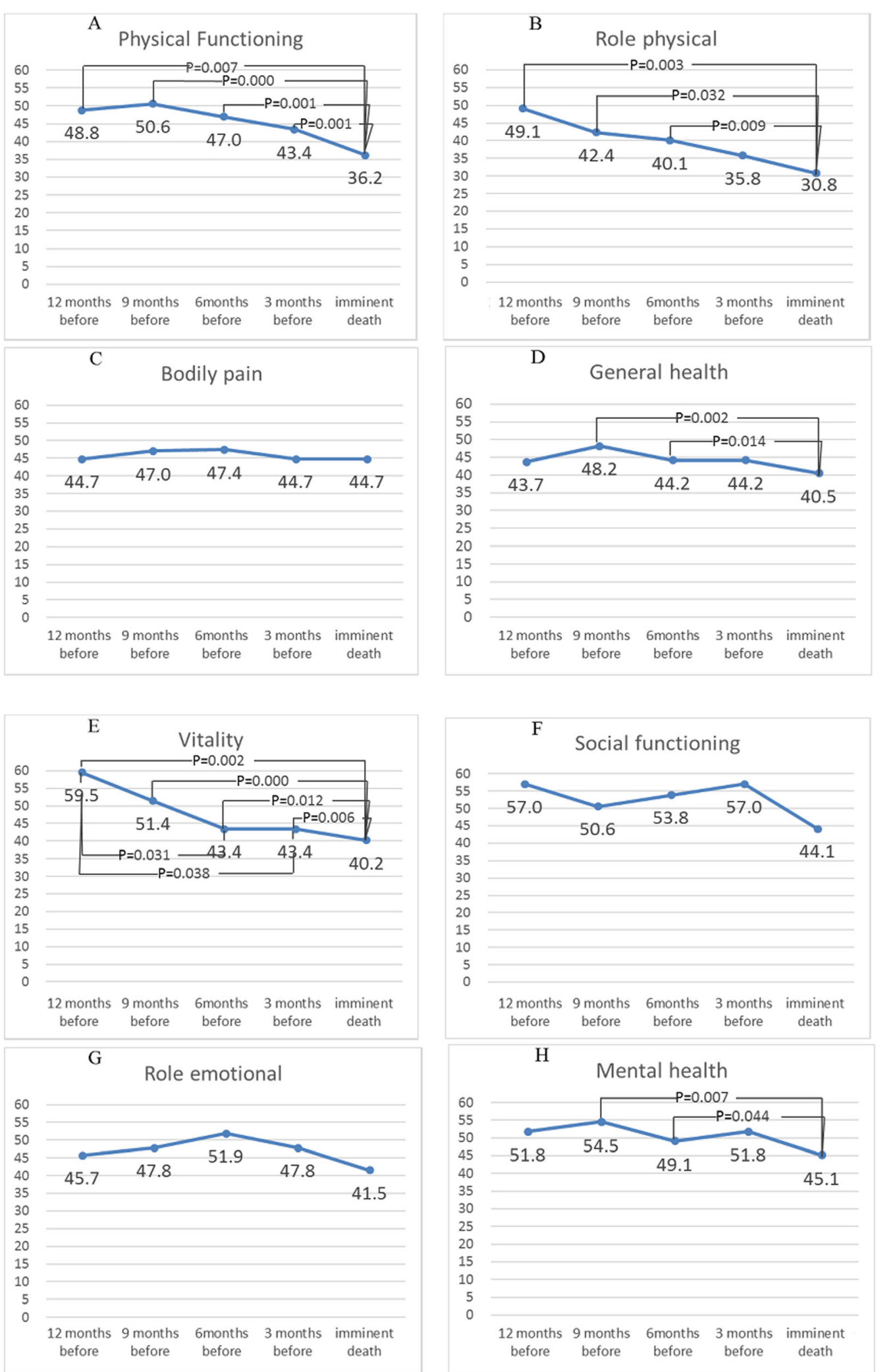

Fig. 1 (See legend on next page.) 
(See figure on previous page.)

Fig. 1 Time-point comparison of changes in HRQOL domain scores in the 12 months prior to death. 12 months before, 12 months before death $(n=8) ; 9$ months before, 9 months before death $(n=4) ; 6$ months before, 6 months before death $(n=22) ; 3$ months before, 3 months before death $(n=31)$; imminent death, less than 3 months before death $(n=40) .{ }^{*}$ All values shown are median scores. ${ }^{* *}$ Upper lines show statistically significant differences using Mann-Whitney $U$ test $(P<0.05)$. HRQOL, health-related quality of life

\section{Changes in HRQOL domain scores}

Overall, 13 patients $(24 \%)$ were able to take sorafenib over the course of at least 1 year. These patients maintained HRQOL domain scores $>40$ without any significant decline (Additional file 1: Figure S2 and Table S2). Domain scores were not significantly different between patients who experienced grade 3 adverse effects and those who did not (Additional file 1: Figure S3).

Next, we analyzed the changes in HRQOL domain scores over the 12 months preceding death in the $40 \mathrm{pa}$ tients who died (Fig. 1 and Additional file 1: Table S1).

The psychosocial and pain domains-including bodily pain, general health, social functioning, and mental health—did not demonstrate significant changes, but the scores remained $>40$ points until imminent death. In contrast, physical functioning, role limitations because of physical problems, and vitality domain scores declined continuously and significantly towards death.

\section{The association of HRQOL domain scores and patient characteristics with overall survival and treatment duration}

The median overall survival was 9.6 (IQR: 0.8-16.3) months. Previous curative therapy and a physical functioning domain score $\geq 40$ at baseline were associated

Table 2 Baseline demographic and clinical variables and baseline domain scores associated with overall survival

\begin{tabular}{|c|c|c|c|c|}
\hline \multirow[t]{2}{*}{ Variable } & \multicolumn{2}{|l|}{ Univariate $^{a}$} & \multicolumn{2}{|l|}{ Multivariate $^{a}$} \\
\hline & $\mathrm{HR}(95 \% \mathrm{Cl})$ & $P$ & $\mathrm{HR}(95 \% \mathrm{Cl})$ & $P$ \\
\hline \multicolumn{5}{|l|}{ Baseline characteristics } \\
\hline Age $<70$ y (vs. $\geq 70$ y) & $0.603(0.349-1.258)$ & 0.208 & & \\
\hline Sex, male (vs. female) & $0.544(0.254-1.167)$ & 0.118 & & \\
\hline HCV infection (vs. other etiology) & $1.138(0.610-0.122)$ & 0.684 & & \\
\hline Child Pugh $=5$ (vs. $\geq 6$ ) & $0.419(0.227-0.812)$ & 0.009 & & \\
\hline TMN stage III (vs. IV) & $0.695(0.371-1.304)$ & 0.257 & & \\
\hline Vascular invasion - (vs. +) & $0.475(0.204-0.945)$ & 0.034 & & \\
\hline Tumor size $<50$ mm (vs. $\geq 50$ mm) & $0.831(0.441-1.567)$ & 0.567 & & \\
\hline Previous curative therapy: Yes (vs. No) & $0.255(0.129-0.504)$ & $<0.001$ & $0.235(0.116-0.477)$ & $<0.001$ \\
\hline AFP $<100$ (vs. $\geq 100)$ & $0.893(0.473-1.686)$ & 0.726 & & \\
\hline DCP $<1000$ (vs. $\geq 1000)$ & $0.548(0.280-1.070)$ & 0.078 & & \\
\hline Initial dose of sorafenib 800 mg (vs. $<800$ mg) & $1.137(0.611-2.115)$ & 0.686 & & \\
\hline Treatment duration $\geq 5$ months (vs. $<5$ ) & $0.608(0.325-1.138)$ & 0.120 & & \\
\hline \multicolumn{5}{|l|}{ HRQOL domain scores $\geq 40^{\mathrm{b}}$ : } \\
\hline Physical functioning & $0.529(0.278-1.008)$ & 0.053 & $0.479(0.245-0.935)$ & 0.031 \\
\hline Role physical & $0.595(0.314-1.127)$ & 0.111 & & \\
\hline Bodily pain & $1.686(0.772-3.676)$ & 0.190 & & \\
\hline General health & $1.331(0.644-2.755)$ & 0.440 & & \\
\hline Vitality & $0.842(0.383-1.848)$ & 0.669 & & \\
\hline Social functioning & $0.833(0.411-1.684)$ & 0.610 & & \\
\hline Role emotional & $0.957(0.473-1.938)$ & 0.904 & & \\
\hline Mental health & $2.053(0.893-4.717)$ & 0.090 & & \\
\hline
\end{tabular}

$H R$ hazard ratio, $\mathrm{Cl}$ confidence interval, $H C V$ hepatitis $C$ virus, $T N M$ tumor-node-metastasis, $A F P$ alpha fetoprotein, DCP des-gamma-carboxy prothrombin, $H R Q O L$ health related quality of life

${ }^{a}$ Cox proportional hazards regression analysis

${ }^{b}$ All domain scores are relative to scores $<40$

All variables with $P$ values $<0.06$ in the univariate analysis were included in the multivariate analysis 
with longer overall survival by multivariate analysis (Table 2 and Fig. 2).

Age, liver function (Child-Pugh score), and HCC stage were not significantly associated with overall survival, neither were serum alpha-fetoprotein or DCP levels. The median duration of sorafenib treatment was 4.9 (IQR: $0.2-10.8)$ months. Social functioning domain scores $\geq 40$ at baseline, absence of vascular invasion, and lower DCP values were significant predictors for longer treatment duration (Table 3 and Fig. 3). The association of social functioning domain scores with treatment duration was confirmed by the competing risk analysis (Additional file 1: Figure S4).

\section{Discussion}

HRQOL was not significantly impaired in the patients who could receive sorafenib treatment over the course of 1 year (Additional file 1: Figure S2 and Table S2). A previous study showed decreased HRQOL domain scores in the 2 months after initiation of sorafenib in patients with advanced HCC because of adverse events [13]. In contrast, sorafenib treatment did not significantly affect HRQOL in patients with metastatic renal cell carcinoma $[9,21]$. We found no significant differences in HRQOL domain scores between patients who experienced grade 3 adverse effects and those who did not (Additional file 1: Figure S3). The severe adverse effects associated with sorafenib use, reported to occur in $50 \%$ of patients [22], potentially influence HRQOL. Interestingly, skin toxicity [23], hypertension [24], and

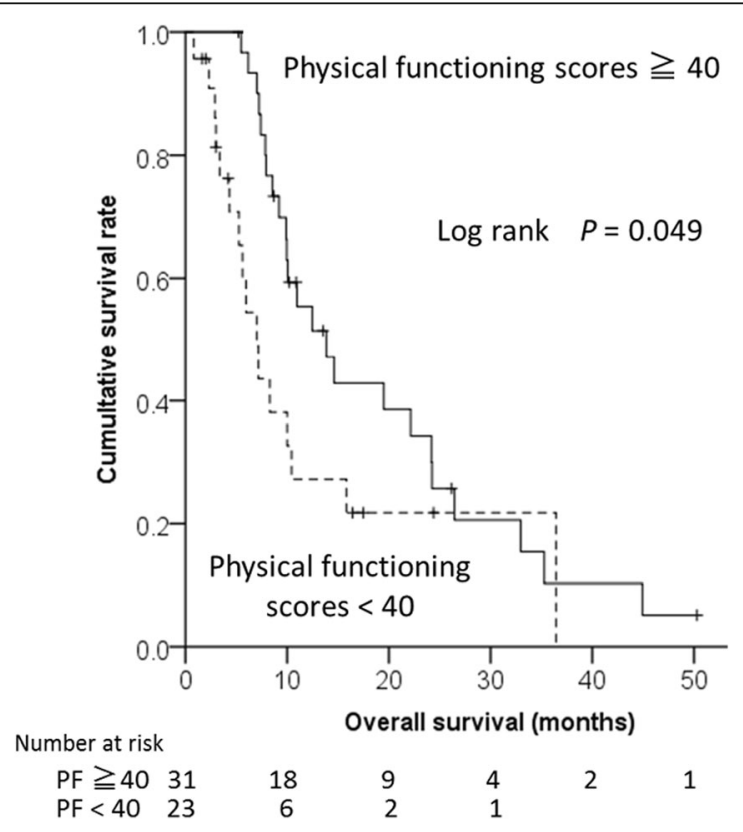

Fig. 2 Kaplan-Meier graphs displaying time-to-death stratified by factors associated with overall survival: physical functioning (PF) scores diarrhea [25] are known to be associated with better prognosis in sorafenib therapy. Therefore, the substantial anti-tumor effects of sorafenib might have countered severe adverse effects both physically and mentally.

Within HRQOL, physical functioning, role limitations because of physical problems (RP), and vitality domain scores gradually decreased towards death. These declines would have reflected the progression of HCC and the deterioration of underlying liver diseases. This is the first prospective long term follow-up study on HRQOL scores in patients with advanced HCC receiving sorafenib therapy. Interestingly, scores in the psychosocial HRQOL domains-social functioning, role limitations because of emotional problems (RE), and mental health-were maintained $>40$ points until death. The bodily pain score also remained $>40$, suggesting that the psychosocial domains and bodily pain can be managed well by periodical medical and nursing interventions. Higher physical functioning domain scores at baseline were significantly associated with longer overall survival. Our study also demonstrated that physical functioning decreased significantly towards death. Taken together with the results of Cox regression analysis, physical functioning domain scores could be good predictors of prognosis. These results are in accordance with previous studies, which revealed better physical functioning and role limitations because of physical problems as predictors for longer survival in patients with non-resectable HCC [26] and in those requiring palliative care for HCC [27]. Previous studies suggest that daily physical activity contributes to the decrease in mortality due to liver cancer $[28,29]$. A prospective study is necessary to verify whether adequate levels of physical activity would improve the prognosis of HCC patients. Our study, for the first time, showed that HRQOL domain scores were useful to predict prognosis in patients with advanced HCC receiving sorafenib. Thus, when we observe a decline in physical functioning domain scores, we should pay more careful attention to the patient's condition. These observations are supported by studies of frailty. Frailty is significantly associated with depression [30] and mortality [31] in patients with end-stage liver disease. The impact of frailty on mortality is evident in elderly patients [32]. Given that the Japanese patients with HCC are mostly geriatric (median age in this study: 71 years old), the concept of frailty appears important to predict prognosis [33].

Higher social functioning domain scores at baseline contributed to longer treatment duration. The social functioning domain score might reflect social support associated with adherence to sorafenib. Sufficient social support from the beginning of sorafenib therapy would be helpful to continue medication, which is potentially accompanied by severe adverse effects. We also found that the presence of vascular invasion and a DCP value 
Table 3 Baseline demographic and clinical variables and domain scores associated with treatment duration

\begin{tabular}{|c|c|c|c|c|}
\hline \multirow[t]{2}{*}{ Variables } & \multicolumn{2}{|l|}{ Univariate $^{a}$} & \multicolumn{2}{|l|}{ Multivariate $^{a}$} \\
\hline & $\mathrm{HR}(95 \% \mathrm{Cl})$ & $P$ value & HR $(95 \% \mathrm{Cl})$ & $P$ value \\
\hline \multicolumn{5}{|l|}{ Baseline characteristics } \\
\hline Age $<70$ y (vs. $\geq 70$ y) & $0.749(0.343-1.429)$ & 0.380 & & \\
\hline Sex, male (vs. female) & $0.634(0.307-1.308)$ & 0.217 & & \\
\hline HCV infection (vs. other etiology) & $1.796(0.964-3.348)$ & 0.065 & & \\
\hline Child Pugh = 5 (vs. $\geq 6$ ) & $0.511(0.271-0.962)$ & 0.038 & & \\
\hline TMN stage III (vs. IV) & $0.672(0.357-1.264)$ & 0.218 & & \\
\hline Vascular invasion - (vs. +) & $0.355(0.178-0.710)$ & 0.003 & $0.382(0.186-0.786)$ & 0.009 \\
\hline Tumor size <50 mm (vs. $\geq 50$ mm) & $0.777(0.412-1.466)$ & 0.432 & & \\
\hline Previous curative therapy: Yes (vs. No) & $0.433(0.226-0.829)$ & 0.012 & & \\
\hline AFP $<100$ (vs. $\geq 100)$ & $1.048(0.561-1.961)$ & 0.954 & & \\
\hline DCP $<1000$ (vs. $\geq 1000)$ & $0.473(0.509-0.912)$ & 0.025 & $0.509(0.261-0.993)$ & 0.048 \\
\hline Initial dose of sorafenib 800 mg (vs. $<800$ mg) & $0.744(0.388-1.426)$ & 0.373 & & \\
\hline \multicolumn{5}{|l|}{ HRQOL domain scores $\geq 40:^{b}$} \\
\hline Physical functioning & $0.956(0.509-1.799)$ & 0.889 & & \\
\hline Role physical & $0.771(0.416-1.429)$ & 0.408 & & \\
\hline Bodily pain & $1.582(0.728-3.436)$ & 0.247 & & \\
\hline General health & $1.034(0.516-2.070)$ & 0.926 & & \\
\hline Vitality & $1.534(0.631-3.731)$ & 0.346 & & \\
\hline Social functioning & $0.395(0.185-0.840)$ & 0.016 & $0.452(0.206-0.995)$ & 0.049 \\
\hline Role emotional & $0.898(0.455-1.770)$ & 0.755 & & \\
\hline Mental health & $0.833(0.379-1.828)$ & 0.649 & & \\
\hline
\end{tabular}

HR hazard ratio, CI confidence interval, HCV hepatitis C virus, TNM tumor-node-metastasis, AFP alpha fetoprotein, DCP des-gamma-carboxy prothrombin; HRQOL, health related quality of life

${ }^{a}$ Cox proportional hazards regression analysis

${ }^{\mathrm{b}}$ All domain scores are relative to scores $<40$

All variables with $P$ values $<0.05$ in the univariate analysis were included in the multivariate analysis

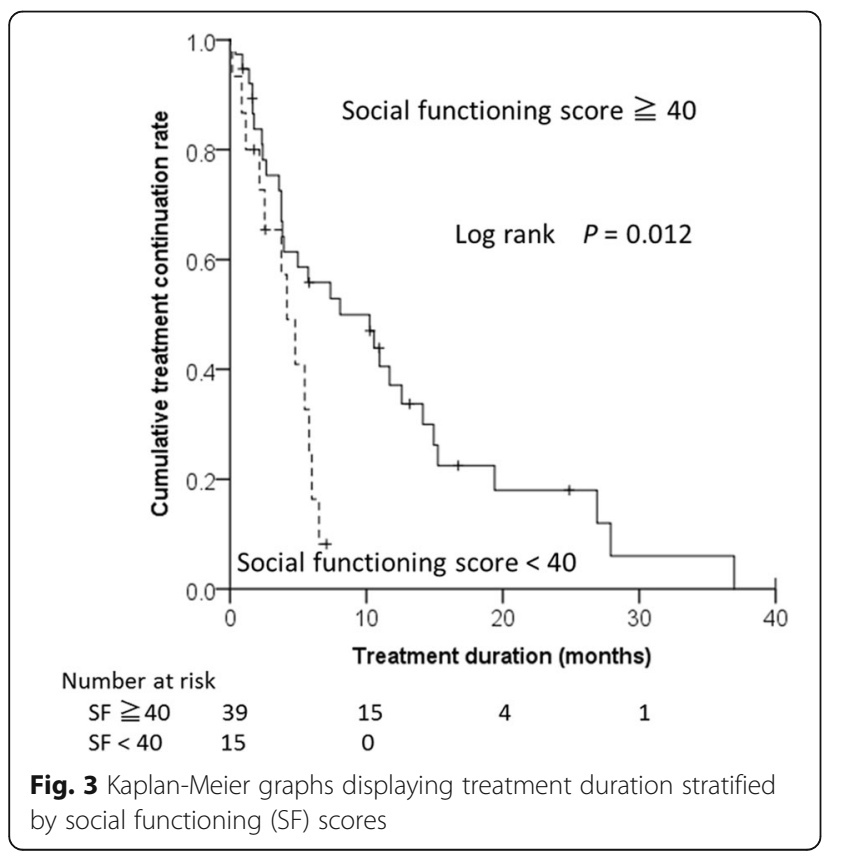

$>1000 \mathrm{mAU} / \mathrm{mL}$ were significant predictors of shorter treatment duration. Tumors with vascular invasion [34] or an associated high level of DCP [35] are likely to have an aggressive phenotype.

Many studies associate preserved liver function with better survival [36], however, Child-Pugh score as an index of liver function was not chosen as a significant predictor for overall survival in this study. The reason for this discrepancy can be explained by the background of our cohort; liver function was well preserved in most patients (Child-Pugh score 5: $59 \%$, score 6: $32 \%$, and score 7: $9 \%$ ).

Different etiologies can influence the interpretation of the results of clinical studies. The major causes of HCC in this cohort were HCV (44 \%), HBV (20\%), and alcohol (13\%). A similar trend is seen in Europe and North America [37], where the leading causes of HCC are HCV (50-70 \%), HBV (20-30\%), and alcohol (20\%). Hence, our results could be applicable to such areas.

The presence of previous curative therapy was significantly associated with better overall survival. The 
difference in the biological nature of tumors may explain these results. Tumors that recur after curative treatment may be less aggressive than other tumors.

There are some limitations to this study. Although the study was prospective, it was conducted in a single institution with a relatively small number of patients. The initial dose of sorafenib used in our study was $800 \mathrm{mg}$, but lower doses were used for some elderly patients. Thus, initial doses were relatively low compared with those used in a previous study [38]. However, the initial dose did not affect prognosis in the present study. Nevertheless, we cannot deny a potential influence of initial sorafenib dose on overall survival and treatment duration.

\section{Conclusions}

In conclusion, HRQOL was not significantly impaired in patients who could receive sorafenib treatment over the course of 1 year. Physical functioning scores $\geq 40$ and social functioning scores $\geq 40$ at baseline were significantly associated with longer overall survival and longer treatment duration, respectively. Thus, HRQOL could be a valuable marker to predict the clinical course of patients with advanced $\mathrm{HCC}$ receiving sorafenib.

\section{Additional file}

Additional file 1: Table S1. Changes in HRQOL domain scores in the 12 months prior to death. Table S2. Changes in HRQOL domain scores in patients who survived $>1$ year $(n=13)$. Figure S1. Graphical display of the distribution of sorafenib-related adverse events $(n=54)$. Figure $\mathbf{S 2}$. Graphical representation of HRQOL domain score changes of patients receiving sorafenib over the course of one year $(n=13)$. Figure $\mathbf{S 3}$ Graphical representation of HRQOL domain score changes with/without grade 3 adverse events. Figure S4. Cumulative discontinuation incidence curves stratified by factors associated with treatment duration: social functioning (SF) scores. (DOCX $553 \mathrm{~kb}$ )

\section{Abbreviations}

AFP: Alpha fetoprotein; BP: Bodily pain; CT: Computed tomography; DCP: Des-gamma-carboxy prothrombin; GH: General health; HCC: Hepatocellular carcinoma; HCV: Hepatitis C virus; HRQOL: Health-related quality of life; IQR: Interquartile range; MH: Mental health; MRI: Magnetic resonance imaging; PF: Physical functioning; RE: Role emotional; RP: Role physical; SF: Social functioning; TNM: Tumor-node-metastasis; VT: Vitality

\section{Acknowledgements}

We express our thanks to all patients who took part in this clinical research. We thank all the members of Department Nursing Tokai University Hospital for discussion and comments.

\section{Funding}

Shomura M received a JSPS KAKENHI Grant-in-Aid for Scientific Research (C) 25463445 from 2012 to 2016.

\section{Availability of data and materials}

All data related to this study are present in the manuscript.

\section{Authors' contributions}

MS and TK contributed equally to this study. MS, TK, KS, SH, YA, and KT provided sorafenib therapy to the patients; TK, KS, SH, YA, and KT, and TM evaluated the efficacy of therapy; MS, TK, HO, and ST collected patients' data, performed the statistical analysis, and were involved in writing and editing the manuscript; MS designed the study and provided financial support for this work. All authors read and approved the final manuscript.

\section{Competing interests}

The authors declare that they have no competing interests.

\section{Consent for publication}

Not applicable.

\section{Ethics approval and consent to participate}

This study was conducted in accordance with the Declaration of Helsinki (2013) of the World Medical Association. The Institutional Review Board of Tokai University (NO.10R-046) approved the study. All patients provided written informed consent.

\section{Précis}

HRQOL was not significantly impaired in patients who received sorafenib treatment over the course of one year. Certain HRQOL domains could be a valuable marker to predict the clinical course of HCC patients receiving sorafenib.

\section{Author details}

${ }^{1}$ Department of Nursing, Tokai University School of Health Sciences, Isehara, Kanagawa, Japan. ${ }^{2}$ Division of Gastroenterology, Department of Internal Medicine, Tokai University School of Medicine, Isehara, Kanagawa, Japan. ${ }^{3}$ University of Nagasaki Department of Nursing, Nagasaki, Nagasaki, Japan.

${ }^{4} 143$ Shimokasuya, Isehara-city, Kanagawa 259-1193, Japan.

Received: 27 April 2016 Accepted: 28 October 2016

Published online: 11 November 2016

\section{References}

1. Jemal A, Bray F, Center MM, Ferlay J, Ward E, Forman D. Global cancer statistics. CA Cancer J Clin. 2011;61:69-90. doi:10.3322/caac.20107.

2. Cheng AL, Kang YK, Chen Z, Tsao CJ, Qin S, Kim JS, et al. Efficacy and safety of sorafenib in patients in the Asia-Pacific region with advanced hepatocellular carcinoma: a phase III randomised, double-blind, placebo-controlled trial. Lancet Oncol. 2009;10:25-34. doi:10.1016/s1470-2045(08)70285-7.

3. Llovet JM, Ricci S, Mazzaferro V, Hilgard P, Gane E, Blanc JF, SHARP Investigators Study Group, et al. Sorafenib in advanced hepatocellular carcinoma. N Engl J Med. 2008;359:378-90. doi:10.1056/NEJMoa0708857.

4. Dancey J, Zee B, Osoba D, Whitehead M, Lu F, Kaizer L, et al. Quality of life scores: an independent prognostic variable in a general population of cancer patients receiving chemotherapy. The National Cancer Institute of Canada Clinical Trials Group. Qual Life Res. 1997:6:151-8.

5. Braun DP, Gupta D, Staren ED. Quality of life assessment as a predictor of survival in non-small cell lung cancer. BMC Cancer. 2011;11:353. doi:10.1186/ 1471-2407-11-353.

6. Braun DP, Gupta D, Grutsch JF, Staren ED. Can changes in health related quality of life scores predict survival in stages III and IV colorectal cancer? Health Qual Life Outcomes. 2011;9:62. doi:10.1186/1477-7525-9-62.

7. Steel JL, Geller DA, Robinson TL, Savkova AY, Brower DS, Marsh JW, et al. Health-related quality of life as a prognostic factor in patients with advanced cancer. Cancer. 2014:120:3717-21. doi:10.1002/cncr.28902.

8. Grunwald V, Soltau J, Ivanyi P, Rentschler J, Reuter C, Drevs J. Molecular targeted therapies for solid tumors: management of side effects. Onkologie. 2009;32:129-38. doi:10.1159/000194949.

9. Miyake H, Kurahashi T, Yamanaka K, Kondo Y, Takenaka A, Inoue TA, et al. Impact of sorafenib on health-related quality of life in Japanese patients with metastatic renal cell carcinoma: a prospective evaluation. BJU Int. 2010; 106:1643-7. doi:10.1111/j.1464-410X.2010.09437.x.

10. Trask PC, Bushmakin AG, Cappelleri JC, Bycott P, Liau K, Kim S. Healthrelated quality of life during treatment for renal cell carcinoma: results from a phase II study of axitinib. Acta Oncol. 2008;47:843-51. doi:10.1080/ 02841860802047395

11. Schadendorf D, Amonkar MM, Stroyakovskiy D, Levchenko E, Gogas H, de Braud F, et al. Health-related quality of life impact in a randomised phase III study of the combination of dabrafenib and trametinib versus dabrafenib monotherapy in patients with BRAF V600 metastatic melanoma. Eur J Cancer. 2015;51:833-40. doi:10.1016/j.ejca.2015.03.004. 
12. Nardone B, Hensley JR, Kulik L, West DP, Mulcahy M, Rademaker A, et al. The effect of hand-foot skin reaction associated with the multikinase inhibitors sorafenib and sunitinib on health-related quality of life. J Drugs Dermatol. 2012;11:e61-5.

13. Brunocilla PR, Brunello F, Carucci P, Gaia S, Rolle E, Cantamessa A, et al. Sorafenib in hepatocellular carcinoma: prospective study on adverse events, quality of life, and related feasibility under daily conditions. Med Oncol. 2013;30:345. doi:10.1007/s12032-012-0345-2

14. Boursier J, Cesbron E, Tropet AL, Pilette C. Comparison and improvement of MELD and Child-Pugh score accuracies for the prediction of 6-month mortality in cirrhotic patients. J Clin Gastroenterol. 2009;43:580-5. doi:10.1097/MCG.0b013e3181889468.

15. Minagawa M, Ikai I, Matsuyama Y, Yamaoka Y, Makuuchi M. Staging of hepatocellular carcinoma: assessment of the Japanese TNM and AJCC/UICC TNM systems in a cohort of 13,772 patients in Japan. Ann Surg. 2007;245: 909-22. doi:10.1097/01.sla.0000254368.65878.da.

16. Oken MM, Creech RH, Tormey DC, Horton J, Davis TE, McFadden ET, et al. Toxicity and response criteria of the Eastern Cooperative Oncology Group. Am J Clin Oncol. 1982:5:649-55.

17. Fukuhara S, Bito S, Green J, Hsiao A, Kurokawa K. Translation, adaptation, and validation of the SF-36 health survey for use in Japan. J Clin Epidemiol. 1998;51:1037-44

18. Fukuhara S, Ware Jr JE, Kosinski M, Wada S, Gandek B. Psychometric and clinical tests of validity of the Japanese SF-36 health survey. J Clin Epidemiol. 1998;51:1045-53.

19. Lencioni R, Llovet JM. Modified RECIST (mRECIST) assessment for hepatocellular carcinoma. Semin Liver Dis. 2010;30:52-60. doi:10.1055/s0030-1247132

20. Japan Clinical Oncology Group. Common Terminology Criteria for Adverse Events (CTCAE) v4.0-Japan Clinical Oncology Group. 2009. Available at http:// www.jcog.jp/doctor/tool/CTCAEv4J_20160310.pdf. Accessed 25 Mar 2016.

21. Bukowski R, Cella D, Gondek K, Escudier B. Effects of sorafenib on symptoms and quality of life: results from a large randomized placebo-controlled study in renal cancer. Am J Clin Oncol. 2007;30:220-7. doi:10.1097/01.coc. 0000258732.80710 .05 .

22. Koldenhof J Jitteveen PO, de Vos R, Walraven M, Tillier CN, Verheul HM, et al. Symptoms from treatment with sunitinib or sorafenib: a multicenter explorative cohort study to explore the influence of patient-reported outcomes on therapy decisions. Support Care Cancer. 2014;22:2371-80. doi:10.1007/s00520-014-2223-2.

23. Shomura M, Kagawa T, Shiraishi K, Hirose S, Arase Y, Koizumi J, et al. Skin toxicity predicts efficacy to sorafenib in patients with advanced hepatocellular carcinoma. World J Hepatol. 2014;6:670-6. doi:10.4254/wjh.v6.i9.670.

24. Estfan B, Byrne M, Kim R. Sorafenib in advanced hepatocellular carcinoma: hypertension as a potential surrogate marker for efficacy. Am J Clin Oncol. 2007;36:319-24. doi:10.1097/COC.0b013e3182468039.

25. Koschny R, Gotthardt D, Koehler C, Jaeger D, Stremmel W, Ganten TM. Diarrhea is a positive outcome predictor for sorafenib treatment of advanced hepatocellular carcinoma. Oncology. 2013;84:6-13. doi:10.1159/ 000342425.

26. Yeo W, Mo FK, Koh J, Chan AT, Leung T, Hui P, et al. Quality of life is predictive of survival in patients with unresectable hepatocellular carcinoma. Ann Oncol. 2006;17:1083-9. doi:10.1093/annonc/mdl065.

27. Diouf M, Filleron T, Barbare JC, Fin L, Picard C, Bouché O, et al. The added value of quality of life (QoL) for prognosis of overall survival in patients with palliative hepatocellular carcinoma. J Hepatol. 2013;58:509-21. doi:10.1016/j. jhep.2012.11.019.

28. Behrens G, Matthews CE, Moore SC, Freedman ND, McGlynn KA, Everhart JE, et al. The association between frequency of vigorous physical activity and hepatobiliary cancers in the NIH-AARP Diet and Health Study. Eur J Epidemiol. 2013;28:55-66. doi:10.1007/s10654-013-9767-1.

29. Ukawa S, Tamakoshi A, Wakai K, Kurozawa Y. Associations of daily walking and television viewing time with liver cancer mortality: findings from the Japan Collaborative Cohort Study. Cancer Causes Control. 2014:25:787-93. doi:10.1007/s10552-014-0380-8

30. Cron DC, Friedman JF, Winder GS, Thelen AE, Derck JE, Fakhoury JW, et al. Depression and frailty in patients with end-stage liver disease referred for transplant evaluation. Am J Transplant. 2016;16:1805-11. doi:10.1111/ajt.13639.

31. Lai JC, Feng S, Terrault NA, Lizaola B, Hayssen H, Covinsky K. Frailty predicts waitlist mortality in liver transplant candidates. Am J Transplant. 2014;14: 1870-9. doi:10.1111/ajt.12762.
32. Chang SF, Lin PL. Frail phenotype and mortality prediction: a systematic review and meta-analysis of prospective cohort studies. Int J Nurs Stud. 2015;52:1362-74. doi:10.1016/j.jinurstu.2015.04.005.

33. Gill TM, Gahbauer EA, Han L, Allore HG. Trajectories of disability in the last year of life. N Engl J Med. 2010;362:1173-80. doi:10.1056/NEJMoa0909087.

34. Sinn DH, Cho JY, Gwak GY, Paik YH, Choi MS, Lee JH, et al. Different survival of Barcelona clinic liver cancer stage $C$ hepatocellular carcinoma patients by the extent of portal vein invasion and the type of extrahepatic spread. PLoS One. 2015;10, e0124434. doi:10.1371/journal.pone.0124434.

35. Miyahara K, Nouso K, Morimoto Y, Tomoda T, Kobayashi S, Takeuchi Y, et al. Evaluation of the effect of sorafenib using serum NX-des- $\gamma$ carboxyprothrombin in patients with hepatocellular carcinoma. Hepatol Res. 2013:43:1064-70.

36. Farinati F, Vitale A, Spolverato G, Pawlik TM, Huo TL, Lee YH, et al. Development and validation of a new prognostic system for patients with hepatocellular carcinoma. PLoS Med. 2016;13, e1002006. doi:10.1371/journal. pmed.1002006.

37. Forner A, Llovet JM, Bruix J. Hepatocellular carcinoma. Lancet. 2012;31(379): 1245-55. doi:10.1016/S0140-6736(11)61347-0.

38. Montella L, Addeo R, Cennamo G, Vincenzi B, Palmieri R, Sperlongano $P$, et al. Sorafenib in elderly patients with advanced hepatocellular carcinoma: a case series. Oncology. 2013:84:265-72. doi:10.1159/000345558.

\section{Submit your next manuscript to BioMed Central and we will help you at every step:}

- We accept pre-submission inquiries

- Our selector tool helps you to find the most relevant journal

- We provide round the clock customer support

- Convenient online submission

- Thorough peer review

- Inclusion in PubMed and all major indexing services

- Maximum visibility for your research

Submit your manuscript at www.biomedcentral.com/submit
) Biomed Central 